\title{
¿Doctor, habla español? Increasing the Supply and Quality of Language-Concordant Physicians for Spanish-Speaking Patients
}

\author{
Alicia Fernández, $M D^{7}$ and Eliseo J. Pérez-Stable, $M D^{2}$ \\ 'Division of General Internal Medicine, San Francisco General Hospital, Department of Medicine, University of California at San Francisco, San \\ Francisco, CA, USA; ${ }^{2}$ Division of General Internal Medicine, Department of Medicine, Medical Effectiveness Research Center for Diverse \\ Populations, University of California at San Francisco, San Francisco, CA, USA.
}

J Gen Intern Med 30(10): 1394-6

DOI: $10.1007 / \mathrm{s} 11606-015-3436-\mathrm{x}$

(C) Society of General Internal Medicine 2015

\begin{abstract}
A s of 2013, there were an estimated 54 million Latinos in the U.S., and at $17 \%$, they represent the largest minority racial/ethnic group. ${ }^{1}$ In the Americas, only Mexico has a larger Latino population. About 16 million people in the U.S. speak Spanish at home and have limited English proficiency (LEP) - speaking English less than "very well"-with about 9 million reporting that they speak English "not at all" or "not well." "While still concentrated in the states of Florida, California, Texas, New Jersey, Illinois and New York, Spanishspeaking monolingual patients are now encountered in nearly every healthcare system in the U.S., and the greatest growth in the past decade has occurred in non-portal states. Millions of patients struggle with language barriers in navigating health care systems and communicating with their doctors; their clinicians struggle too. Language barriers are associated with lower patient comprehension, satisfaction, and trust in physicians, and often, worse clinical outcomes. ${ }^{3,4}$ For clinicians, language barriers can invoke dread, with visions of wasted time, communication frustration, and increased difficulty in providing high-quality care. ${ }^{5}$ Finally, patient safety suffers when language barriers impede easy communication. ${ }^{6}$

In this context, the study by Morales and colleagues in this issue of JGIM brings welcome news. ${ }^{7}$ About $75 \%$ of medical schools now offer or plan to shortly offer a Spanish language curriculum to medical students. As the majority of these courses are electives, and course credit is not consistently granted, it is unclear how many students actually participate. About half the schools reported that the Spanish course offering was driven by student interest; this is additional welcome news, as clearly, many physicians of tomorrow wish to care for diverse populations. In addition, the offering of a Spanish language course reflects some level of institutional interest in meeting the needs of the patient populations served.

Patients want a physician who speaks their language well enough to supply excellent care. As the study authors note, it is disconcerting that language proficiency
\end{abstract}

Published online July 25, 2015 usually went untested or was tested using non-standard methods after completion of the course. More disconcerting still is that over half the schools who offer a course subsequently allow students to serve as interpreters or to take histories in Spanish, without establishing language competence in a standardized way. Physicians and medical students tend to overestimate their language skills and underutilize professional interpreters, leading to a culture of "getting by." 89 False fluency is associated with medical errors. Patient-physician communication is also becoming more complex. In the era of electronic medical records, with patient access to physicians via Web-based email portals, written communication is increasingly important. Visit summaries with specific instructions may also need to be written in Spanish. For safety, physician competence in written Spanish may need to be evaluated as well. We agree with the authors that Spanish language courses should target intermediate and advanced students and should routinely incorporate testing for spoken, and possibly written, language proficiency into their design.

In response to the growing awareness of the clinical implications of language barriers, some health care systems are increasingly testing their bilingual staff, and in the process are discovering that many "Spanish speakers" (including some heritage speakers) have only basic language skills, which may suffice for simple communication tasks but are not adequate for the complex communication demanded by routine clinical care. Relying on self-reporting of Spanish language proficiency is possible only when physicians work in systems that offer no incentives to care for Spanish-speaking patients. Kaiser Permanente in Southern California, for example, appropriately tests physicians via formal language testing before considering them to be Spanish speaking, in part because they offer a bilingual pay incentive to clinicians caring for Spanish-speaking patients. In addition, self-reporting of Spanish proficiency is useful only at the extremes of responses. In a simple study we carried out with colleagues in San Francisco, physicians who evaluated their Spanish as "fair" rather than "very good" or "excellent" were equally likely to be rated as non-Spanish-speaking by their patients as to be rated Spanishspeaking. ${ }^{10}$ In a separate study, we are finding that typically only those physicians who evaluate their Spanish fluency as "excellent" have confidence in carrying out complex, yet 
routine, communication tasks such as an advanced directives discussion or medication reconciliation.

Ensuring an adequate supply of Spanish-speaking physicians will take more than medical school elective courses, regardless of how well they are designed and executed. It is past time for the health care system to systematically address the language needs of Spanish-speaking patients via policy changes.

First, healthcare systems should certify the skills of Spanish-speaking physicians before allowing them to care for patients without an interpreter. There are several commercially available proficiency tests that are focused on Spanish, include medical terms, and are readily administered in person or over the phone. Other professionals including diplomats, police officers, and teachers already use similar tests to demonstrate competence. We recommend that bilingual certification be a requirement for physicians before they can opt not to use professional interpreters, and that it becomes a standard quality-of-care metric in caring for LEP patients. Physicians who work alone or in small practices might consider formal language testing for marketing purposes ("certified Spanishspeaker") as well as quality of care. In the absence of a bilingual clinician in the practice, all physicians should be aware of the errors associated with false fluency and should consider whether their fluency level is appropriate to the specific clinical challenge, and use professional interpreters when necessary, as ad hoc interpreters also lead to lower quality of care.

Second, the supply of Spanish-speaking physicians can be increased by considering Spanish fluency as one of the criteria for medical school admissions. Californians will certainly get better care if the UC medical schools systematically consider demonstrated fluency in one of the five most commonly spoken non-English languages in California as an additional criterion for admission. Other states with large LEP populations and state medical schools could do the same. While some work would be needed to determine how adequate language skills would be demonstrated and how much weight they should be given in considering an applicant's academic portfolio, a formal policy to favor applicants with regional language skills would be an easy place to start. A more assertive policy option would be to require a successful candidate to demonstrate local language skills, such as proficiency in Spanish or Cantonese in California. The ability to communicate directly with local patients is certainly as useful and necessary to a practicing physician as a basic knowledge of organic chemistry.

A third policy lever is to reward certified speakers of needed local languages, such as Spanish. As noted above, some systems are already doing this, while others, including Kaiser Permanente in northern California, offer only optional testing and no financial reward. At UCSF Health, there is a proposal to provide small financial rewards to language-certified faculty clinicians for each concordant visit that saves interpretation resources. Financial incentives signal the importance of direct communication, reward physicians who use less interpreter resources - which are themselves expensive - and incentivize the care of LEP patients. Some systems have already noted that physicians are hesitant to declare themselves Spanish speakers for fear of being flooded with hard-to-care-for LEP patients. Financial incentives, as well as adequate support systems, would help address this.

Morales and coauthors also raised two additional issues. Care of LEP patients is often placed in the context of clinical cultural competence. Although language concordance and cultural competence are often closely related, they are distinct skills that need to be addressed separately. All clinicians must have the skills necessary to deliver effective care for patients in a cross-cultural relationship, regardless of whether they speak the patient's language or communicate via a professional interpreter. Clearly, not all clinicians need to be certified in a non-English language. The authors also raise other issues that can make communication with LEP patients challenging, such as inadequate health literacy and very low levels of formal education. In our experience, these common barriers make language fluency even more important.

The number of Spanish-speaking LEP patients in the U.S. is so large that it is hard to grasp. To help place it in a numeric context, consider this: the most conservative estimate of 9 million Spanish-speaking LEP people (approximately 3.5\% of the U.S. population) is higher than the number of patients with schizophrenia $(1 \%)$, rheumatoid arthritis $(<1 \%)$, cirrhosis $(0.27 \%)$, and end-stage renal disease $(0.3 \%)$ combined. As a country, we have, quite appropriately, put in place systems and guidelines to care for patients with complex medical problems and needs. It is time to get serious about ensuring a supply of competent physicians to care for Spanish-speaking patients.

Acknowledgments: This work was funded in part by the Resource Centers for Minority Aging Research program of the National Institute on Aging, National Institutes of Health (NIH) (P3O AG15272) (EPS), and by NIH K24DK102057-02 (AF).

Conflict of Interest: The authors declare that they do not have a conflict of interest.

Corresponding Author: Alicia Fernández, MD; Division of General Internal Medicine, San Francisco General Hospital, Department of Medicine, University of California at San Francisco, San Francisco, CA 94110, USA (e-mail: afernandez@medsfgh.ucsf.edu).

\section{REFERENCES}

1. US Census Bureau. Annual Estimates of the Resident Population by Sex, Age, Race, and Hispanic Origin for the United States and States: April 1, 2010 to July 1, 2013. 2013 Population Estimates 2014.

2. Language Data from the American Community Survey. U.S. Census Bureau 2013; http://factfinder.census.gov/faces/tableservices/jsf/ pages /productview.xhtml?pid=ACS_13_5YR_B16006\&prodType=table. Accessed 5/29/15.

3. Fernandez A, Schillinger D, Warton EM, et al. The Impact of Language Barriers on Poor Glycemic Control Among Insured Latinos with Diabetes: data from the DISTANCE Study. J Gen Intern Med. 2009;24(SI):S185.

4. Schenker Y, Karter AJ, Schillinger D, et al. The impact of limited English proficiency and physician language concordance on reports of clinical interactions among patients with diabetes: the DISTANCE study. Patient Educ Couns. 2010;81(2):222-8. 
5. Karliner LS, Perez-Stable EJ, Gildengorin G. The language divide. The importance of training in the use of interpreters for outpatient practice. J Gen Intern Med. 2004; 19(2): 175-83.

6. Divi C, Koss RG, Schmaltz SP, Loeb JM. Language proficiency and adverse events in US hospitals: a pilot study. Int $\mathrm{J}$ Qual Health Care. 2007;19(2):60-7.

7. Morales R, Rodriguez L, Singh A, et al. National Survey of Medical Spanish Curriculum in U.S. Medical Schools. J Gen Intern Med. 2015. doi:10.1007/s11606-015-3309-3.
8. Diamond LC, Schenker Y, Curry L, Bradley EH, Fernandez A. Getting by: underuse of interpreters by resident physicians. J Gen Intern Med. 2009;24(2):256-62.

9. Reuland DS, Frasier PY, Olson MD, Slatt LM, Aleman MA, Fernandez A. Accuracy of self-assessed Spanish fluency in medical students. Teach Learn Med. 2009;21(4):305-9.

10. Rosenthal A, Wang F, Schillinger D, Perez Stable EJ, Fernandez A. Accuracy of physician self-report of Spanish language proficiency. J Immigr Minor Health. 2011;13(2):239-43. 